\title{
Experience with tacrolimus in children with steroid-resistant nephrotic syndrome
}

\author{
Lavjay Butani • Rajendra Ramsamooj
}

Received: 3 November 2008 /Revised: 27 April 2009/Accepted: 28 April 2009/Published online: 5 June 2009

(C) The Author(s) 2009. This article is published with open access at Springerlink.com

\begin{abstract}
Children with steroid-resistant nephrotic syndrome (SRNS) are at risk of developing renal failure. We report here the results of a single-center retrospective observational study of the remission rate in pediatric patients with SNRS receiving tacrolimus. Serial renal biopsies from children on tacrolimus therapy were evaluated for tubulointerstitial fibrosis and transforming growth factor- $\beta$ immunostaining. Of the 16 children with SRNS, 15 went into complete remission after a median of 120 days of therapy. Nine children were able to stop steroids, while the others were on tapering doses. Forty-seven percent had relapses, most of which were steroid-responsive. Serial renal biopsies were obtained from seven children after a median treatment duration of 24 months; two of these children had increased tubulointerstitial fibrosis and four showed increased transforming growth factor- $\beta$ tissue staining. Children with worsening histological findings were younger. There was no significant association between tacrolimus exposure and biopsy changes, although the average trough level was higher in those children with worsening histological findings. In conclusion, tacrolimus may be a safe and effective alternative agent for inducing remission in children with SRNS. However, caution needs to be taken when prescribing this agent due to its narrow therapeutic index. Serial renal biopsies are necessary to
\end{abstract}

\footnotetext{
L. Butani $(\bowtie)$

Department of Pediatrics,

University of California Davis Children's Hospital,

2516 Stockton Boulevard,

Sacramento, CA 95817, USA

e-mail: Lavjay.butani@ucdmc.ucdavis.edu

R. Ramsamooj

Department of Pathology,

University of California Davis Medical Center,

Sacramento, CA, USA
}

check for subclinical nephrotoxicity, especially in younger children and those with higher trough levels.

Keywords Calcineurin inhibitor - Glomerulonephritis . Nephrosis $\cdot$ Nephrotoxicity $\cdot$ Pediatric

\section{Introduction}

Although steroid resistant nephrotic syndrome (SRNS) represents a small fraction of all pediatric nephrotic syndrome (NS) cases, it contributes disproportionately to end stage renal disease (ESRD) [1]. Renal survival rates vary somewhat based on the underlying histology but average $50-60 \%$ for children with idiopathic focal segmental glomerulosclerosis (FSGS), the most common histology in pediatric SRNS [2]. Notwithstanding the risk of progressive renal impairment in children with SRNS, the successful induction of remission, even partial, is associated with the preservation of renal function and excellent longterm outcome [2, 3]. Several different therapies have been attempted, all with variable degrees of success. Some of the more commonly used ones include cyclophosphamide (CPM) [4, 5], cyclosporine (CyA) [6, 7] and various combinations of these. All of these approaches have problems. Some entail the need for repeated peripheral intravenous (IV) access (or a more permanent central venous access) [8]; others have been associated with serious infections [9]. Therapy with CyA has its own unique problems, including relapses after withdrawal [10, 11], the development of secondary CyA resistance [11, 12] and CyA toxicity [11].

The data currently available on the use of tacrolimus (Tac), a calcineurin inhibitor (CNI), in children with SRNS are very limited. Theoretically, Tac has many properties that 
make its use preferable compared to CyA, at least in the transplant population where Tac has been shown to be more potent [13], with more reliable monitoring of its exposure using trough determinations $[14,15]$ and lower cosmetic side-effects [13]. Whether these benefits of Tac are also applicable in the setting of NS, where the kinetics are likely different, has not been studied. Nevertheless, at our center, we have been using Tac as the preferred CNI in all settings since July 1995 . The purpose of the study reported here was to describe both the excellent remission rate achieved in our subjects using this approach and the factors associated with subclinical nephrotoxicity as seen on serial renal biopsies in children treated with prolonged courses of Tac. To the best of our knowledge, there are no published data on the histological evolution of SRNS based on follow-up biopsies obtained from children treated with Tac for SRNS.

\section{Methods}

Medical records of children with SRNS evaluated at our center between July 1995 and January 2008 were abstracted for data. Proteinuria was quantitated using the urine protein-to-creatinine ratio $(\mathrm{Up} / \mathrm{c})(\mathrm{mg} / \mathrm{mg})$, and estimated glomerular filtration rate (eGFR) was calculated using the previously validated Schwartz formula [16].

NS

The constellation of nephrotic range proteinuria $(\mathrm{Up} / \mathrm{c}>2.5)$, hypoalbuminemia (serum albumin $<$ $2.5 \mathrm{~g} / \mathrm{dL}$ ) and edema

SRNS Lack of resolution of proteinuria (Up/ $c>0.2$ ) and/or lack of normalization of the serum albumin (serum albumin $<$ $3.5 \mathrm{~g} / \mathrm{dL}$ ), after at least 6 weeks of daily steroid therapy

Complete Normalization of the Up/c $(<0.2)$ and remission (CR) of the serum albumin $(>3.5 \mathrm{~g} / \mathrm{dL})$

Partial remission At least a 50\% reduction in the Up/c but (PR) a lack of normalization, and a serum albumin of $\geq 2.5 \mathrm{~g} / \mathrm{dL}$

Biopsy data All biopsies were re-evaluated in a blinded manner. Trichrome- and hematoxylin/eosin-stained sections were evaluated for the extent of tubular atrophy (TA), interstitial fibrosis (FIB) and arteriolar hyalinosis. The total area of the tissue showing TA and FIB, excluding the subcapsular region, was used to quantitate the extent of TA and FIB. Any significant FIB, even if not in the classic 'striped' pattern was taken into account. Paraffin-imbedded sections of tissue were used to cut new blocks for transforming growth factor (TGF) $-\beta$ staining. The method is described in detail in a previous article [17]. Very briefly, tissue samples were deparaffinized, rehydrated and then allowed to interact overnight with an anti-TGF- $\beta$ antibody for isoforms 1,2 and 3 (Fitzgerald Industries Int, Concord, MA) by an immunoperoxidase technique. Renal tubular immunoreactivity for TGF- $\beta$ isoforms was evaluated, blinded, by assessing the percentage of nuclear staining. Appropriate positive (placenta and kidney) and negative (kidney) controls were used.

Statistical analyses The paired Student's $t$ test was used to compare initial and follow-up laboratory and biopsy data, the Spearman correlation test was used to compare changes in the histology and TGF- $\beta$ staining and the unpaired $t$ test was used to analyze the effect of variables on worsening histology/TGF- $\beta$ staining. Analyses were performed using SPSS software ver. 16.0 (SPSS, Chicago, IL). A $p$ value of $<0.05$ was considered to be statistically significant.

The study was approved by the University of California Davis Institutional Review Board.

\section{Results}

Demographic data During the study period, 22 children with SRNS were treated at our center, 16 of whom are included in this study. Six were excluded since they presented with NS in the context of other genetic/ metabolic disorders or had infantile NS. Ten subjects were male. Ethnicity was as follows: six Caucasian, five Asian, three Hispanic and two African American. Median (range) age at diagnosis was $5.2(2-13.3)$ years. Based on biopsy findings, eight children had FSGS, seven had minimal change disease (MCD) and one had membranous nephropathy.

Initial clinical course of the 16 children in the study, 12 had primary steroid resistance, and four developed secondary resistance at a median of 7 (range 1-13.5) years after diagnosis. Of the 12 children with primary SRNS, five were 'partial responders' in that they had an improvement, but not normalization, of their proteinuria $(\mathrm{Up} / \mathrm{c} 0.2-2.5)$ and a rise, but lack of normalization, of serum albumin (serum albumin 2.5-3.4 g/dL). When treatment with Tac was started, patients had completed a median of 2.6 (range 1.522) months of treatment with oral prednisolone. Four children were still receiving daily steroids, and 12 were on alternate day steroids. Prior to the initiation of Tac therapy, three children had been treated with other immunosuppressive agents, including a combination of IV methylprednisolone and oral CPM $(n=2)$, oral CPM alone $(n=1)$, chlorambucil $(n=1)$ and CyA $(n=1)$. At the start of Tac therapy, ten of the children were receiving either 
angiotensin receptor blockers (ARB) $(n=1)$, angiotensin converting enzyme (ACE) inhibitors $(n=8)$ or both $(n=1)$. The median (range) duration of ACE inhibition/ARB use prior to the start of Tac therapy was $2.5(0.5-15)$ months. Genetic testing for nephrin and podocin mutations was performed in 12 of the 16 children (Athena Diagnostics, Worcester, MA). None of the tested children had mutations in the podocin gene, and three had DNA sequence variations in the nephrin gene. One child had a variation of unknown clinical significance in both gene copies, one had a single gene variant of unknown significance and one was heterozygous for the mutation associated with the Finnish type of congenital NS (with an additional gene variant of unknown clinical significance). None of the patients had familial NS.

The initial median (range) Tac dose, chosen empirically, was $0.1(0.05-0.2) \mathrm{mg} / \mathrm{kg}$ per day. The initial target trough (determined by high-pressure liquid chromatography) was set at $5-10 \mathrm{ng} / \mathrm{mL}$. Data on the serum albumin, Up/c and eGFR at diagnosis, start of Tac therapy and at last followup are presented in Table 1. As seen in Table 1, at the time of the last follow-up visit (median of 22 months after Tac start), all laboratory parameters had improved, with no adverse effect on eGFR.

During follow-up, 15 (94\%) of the subjects went into $\mathrm{CR}$. The one patient with advanced chronic kidney disease at the start of Tac therapy (FSGS on biopsy) was unresponsive to treatment and progressed to ESRD. The median (range) time to PR and CR for the 15 children who responded was 29 (13-180) days and 120 (16-730) days, respectively. Three children were outliers and took> 200 days to go into $\mathrm{CR}$; all 3 had rapidly responded to the initiation of Tac therapy. The time from the start of Tac therapy to the first sign of response $(30 \%$ reduction in the $\mathrm{Up} / \mathrm{c}$ ) in these children was 21 (range 14-129) days. Since the introduction of Tac was the only intervention performed in the time period immediately preceding the noted reduction in proteinuria, these children were assumed to be Tac responders. The temporal pattern of remission after the start of Tac therapy is graphically depicted in Fig. 1. The biopsy revealed that the remission rate was not affected by any underlying histology or the presence of mesangial hypercellularity.

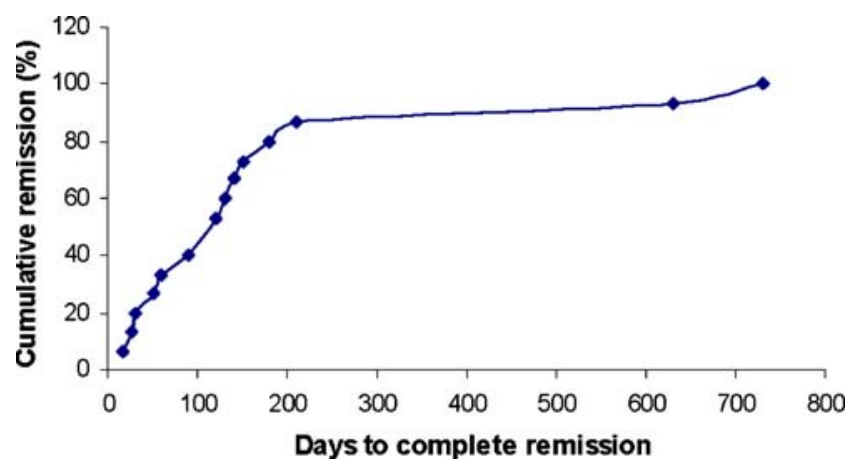

Fig. 1 Temporal pattern of remission after the start of tacrolimus therapy

Final disposition The Tac doses were increased over time as necessary to achieve CR if the patients did not show any acute rise in serum creatinine levels. Dose escalation was at the discretion of the treating nephrologist. At last follow-up, the median (range) Tac doses and trough levels were $0.15(0.06-0.38) \mathrm{mg} / \mathrm{kg}$ per day and $5(1.8-$ 12.3) $\mathrm{ng} / \mathrm{mL}$, respectively. No significant differences were seen in Tac dosing/trough among ethnicities. The mean final Tac trough level in children of Caucasian, Asian, Hispanic and African-American ethnicities was $5.5,5.6,7.3$ and $4.3 \mathrm{ng} / \mathrm{mL}$, respectively $(p=0.17)$; the final Tac dose in these same ethnic groups was $0.12,0.22$, 0.14 and $0.08 \mathrm{mg} / \mathrm{kg}$ per day, respectively $(p=0.87)$. Of the 15 children who responded to Tac, nine were able to come off steroids; six remained on steroids due to steroidresponsive relapses $(n=3)$ or as part of their initial steroidtaper $(n=3)$, only two of whom were receiving daily prednisolone. The longest steroid-free interval for the nine children who were taken off steroids was a median (range) of $28.5(0.1-54)$ months. Seven of the 15 children (47\%) had relapses during attempted steroid-taper, of whom six had steroid-responsive relapses. One child, with FSGS, did not go into remission despite daily prednisolone therapy and was taken off Tac. At last follow-up, of the 15 children, 13 were still receiving Tac. The two who were taken off Tac had frequent relapses and were transitioned to other regimens. Figure 2 depicts the outcomes in the children in the form of a flow-diagram.

Table 1 Comparison of laboratory data at various time points in relation to the start of tacrolimus therapy

\begin{tabular}{lllll}
\hline Laboratory parameter & Initial presentation & Start of Tac & Last follow-up & p (Tac vs. last follow-up) \\
\hline Serum albumin (g/dL) & $1.2(0-2.2)$ & $1.5(0.8-3.5)$ & $3.8(1.4-4.7)$ & $<0.005$ \\
Urine protein/creatinine ratio (mg/mg) & $11(2.8-22)$ & $2.8(0.7-20)$ & $0.09(0-11.4)$ & 0.002 \\
eGFR (mL/min per $\left.1.73 \mathrm{~m}^{2}\right)$ & $148(44-352)$ & $159(29-295)$ & $145(21-246)$ & 0.19 \\
\hline
\end{tabular}

eGFR, Estimated glomerular filtration rate; Tac, tacrolimus

All numerical data are presented as the median, with the range in parenthesis 
Fig. 2 Flow-chart depicting outcomes in study population. $C R$ Complete remission, SRNS steroid-resistant nephrotic syndrome

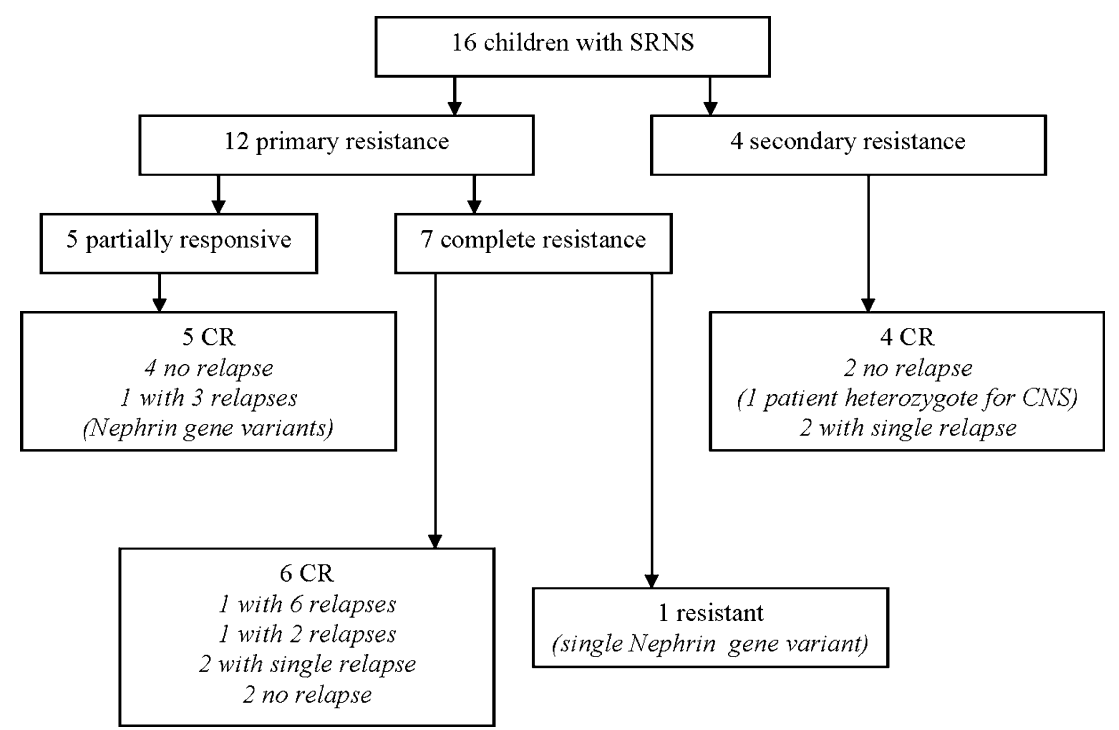

Side effects of therapy One patient needed a temporary discontinuation of Tac therapy due to an acute rise in serum creatinine in the setting of dehydration. With hydration, his renal function improved and Tac was restarted. Two children developed infectious complications, one with Salmonella enteritidis gastroenteritis and another with Streptococcal pneumoniae bacteremia (both were frankly nephrotic when they developed these). Therapy with Tac was resumed once the infection resolved. One child was diagnosed with an Epstein-Barr virus (EBV)-negative Hodgkin's lymphoma 6 months after being on Tac. This child had not been known to have lymphoma at the time of his presentation with NS, and he had not received any other immunosuppressive therapy prior to the start of Tac. No patient developed diabetes.

Serial biopsy data Serial renal biopsies were recommended for all children receiving Tac for $>12$ months $(n=11)$; of these, four children did not undergo a biopsy due to family refusal $(n=3)$ or insurance reasons $(n=1)$. Of the children who had a repeat renal biopsy, five $(71 \%)$ had FSGS, one had MCD and one had membranous nephropathy. The median (range) duration of Tac therapy before the second biopsy was 24 (14-56) months. The median (range) cumulative Tac dose between the two biopsies was 102 $(61-256) \mathrm{mg} / \mathrm{kg}$, and the median (range) of the Tac trough levels between the 2 biopsies was $7.2(3.4-9.5) \mathrm{ng} / \mathrm{ml}$. Although there was no significant increase in the median area with FIB, TA, and tissue staining for any of the isoforms of TGF- $\beta$ between the pre- and post-Tac biopsies, two of the seven children (29\%) showed an increase in their FIB/TA score, four (57\%) had increased tissue staining for TGF- $\beta$ (only one of whom also had changes visible upon light microscopy examination), one child each had increases in TGF- $\beta 2$ and TGF- $\beta 3$ staining and two children had increases in both TGF- $\beta 1$ and TGF- $\beta 2$ staining. There was a strong correlation between changes in FIB and changes in TA between biopsies $(r=0.9, p=0.002)$. However, there was no significant correlation between changes in TGF- $\beta$ staining (for any isoforms) and changes in either FIB or TA, or between changes in the three isoforms of TGF- $\beta$ (all $p>0.05$ ). The biopsies (both initial and repeat) in all patients lacked significant arteriolar hyalinosis. We found no significant association between any demographic parameter/measure of Tac exposure and increased TGF- $\beta$ staining (data not shown). Data on factors associated with increased TA/FIB are depicted in Table 2.

Children with increased TA/FIB were younger. The duration of Tac exposure, cumulative Tac dose and Tac trough levels were not significantly associated with changes in the histological findings. Figure 3 depicts a normal glomerulus with no TGF- $\beta$ tissue staining; Figure 4 is a representative biopsy showing significant and intense TGF- $\beta$ tissue staining.

\section{Discussion}

Children with SRNS continue to be at high risk of complications [18]. Moreover, many of the diseases that present as SRNS in children have a high rate of recurrence after transplantation [19-21]. Therefore, every possible attempt needs to be made to induce remission in such children, while concurrently minimizing the toxicity of the therapeutic regimens. Cyclosporine A has been used as a frequent therapeutic agent in patient with SRNS. However, the long-term use of CyA has been associated with nephrotoxicity, related to arteriolar vasoconstriction, which if prolonged could lead to renal ischemia and FIB [22-24]. 
Table 2 Association between biopsy changes and demographic/Tac exposure variables

\begin{tabular}{llll}
\hline Demographic/Tac exposure variables & Worsening histology & No histological change & $p$ \\
\hline Age (years) & 5.9 & 12.3 & 0.03 \\
Duration of Tac duration (months) & 27.5 & 27 & 0.9 \\
Average inter-biopsy Tac trough $(\mathrm{ng} / \mathrm{mL})$ & 8.4 & 5.4 & 0.16 \\
Inter-biopsy cumulative Tac dose $(\mathrm{mg} / \mathrm{kg})$ & 72 & 160 & 0.16 \\
\hline
\end{tabular}

Serial renal biopsies in children with NS treated with a prolonged course of CyA have shown evidence of FIB and TA in as few as $15-17 \%$ of the patients $[6,10]$ to as high as $57 \%$ [25].

Pediatric experience with Tac in SRNS is limited. Excluding single case reports, few single-center studies have been published to date [5, 26-28]. In 2004, Loeffler et al. described the use of Tac in seven children with SRNS; six achieved $C R$ and one went into PR after a mean duration of 2 months of therapy. At last follow-up, five of the seven were off steroids, although the steroid-free duration was quite short. Bhimma et al. subsequently reported a CR rate of $40 \%$ and a $\mathrm{PR}$ rate of $45 \%$ in 20 South African children with SRNS from idiopathic FSGS who received a 12-month course of Tac. At last follow-up, only five $(25 \%)$ remained in CR. Lastly, Gulati et al. reported a CR rate of $84 \%$ in a cohort of North Indian children treated with Tac and steroids [28]. Our study is the largest reported study on the use of Tac in North American children with SRNS, and the only one, to the best of our knowledge, that has analyzed serial biopsy data. Our success with the use of Tac in pediatric patients with SRNS exceeds previously reported data, with all but one child (94\%) achieving CR. The only child who did not respond had advanced FSGS with an eGFR of $29 \mathrm{~mL} / \mathrm{min}$ per 1.73 surface area. In our experience, children who respond to Tac do so shortly after initiation of Tac, with a median time to laboratory-confirmed improvement of 27 days, although CR may take longer. Most of our children were able to be

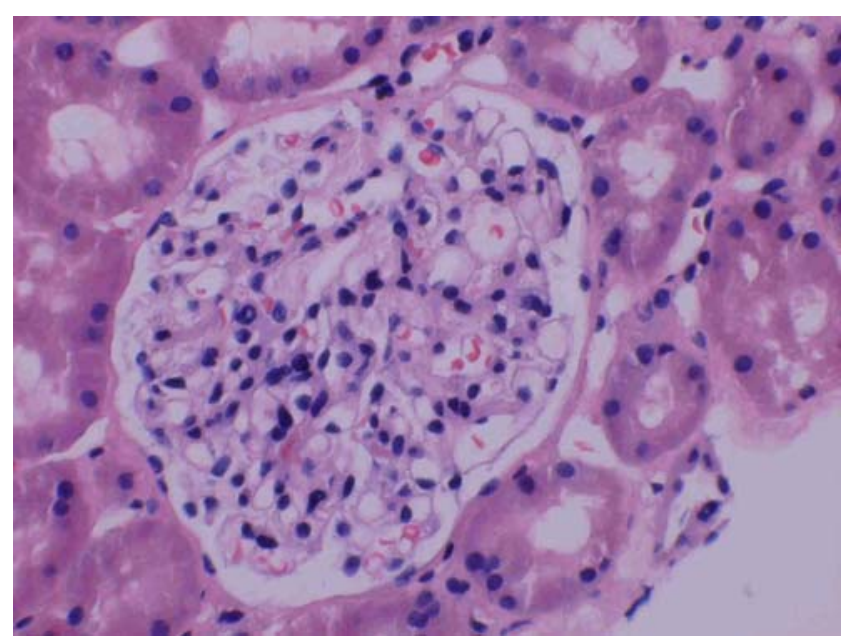

Fig. 3 Biopsy with no transforming growth factor (TGF)- $\beta$ staining tapered off their steroids (60\%). An additional 20\% were still receiving steroids, most of whom were on alternate day steroids and were being slowly weaned off. During the steroid-taper, almost half of the children had relapses, of whom all but one responded to a re-initiation of steroid treatment. These results support the previous observation that CNIs work best when used in combination with steroids. The prolonged use of Tac in these children was associated with relatively little observed toxicity. While we cannot discount a contribution of Tac in predisposing one of our patients to develop lymphoma, the observation that the tumor was EBV negative makes this less likely. Moreover, this child's underlying renal histology showed MCD, which is known to be associated with Hodgkin's lymphoma; the association is even stronger in children with MCD who are steroid-resistant or -dependant [29, 30].

In order to look more closely for subclinical nephrotoxicity, we obtained serial renal biopsies from our patients who went into remission on Tac. Histological examination of these biopsies revealed that two of seven children had increased FIB and TA, suggestive of chronic CNI toxicity, and that four children (57\%) had increases in TGF- $\beta$ tissue expression, with only one of these four also showing changes on light microscopy examination. Transforming growth factor- $\beta$ is a ubiquitous cytokine with very significant fibrogenic properties; it has been shown to be upregulated in the setting of CyA toxicity in the renal transplant population [31]. Similar effects on TGF- $\beta$ expression have been noted with Tac, both in vivo and in vitro

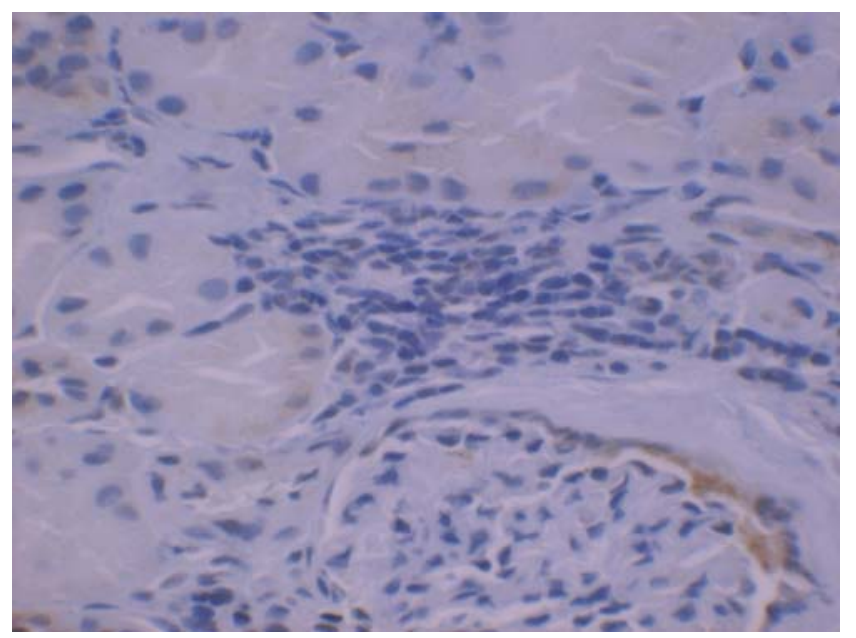

Fig. 4 Biopsy with intense TGF- $\beta$ staining (brown) in renal tubular nuclei 
$[32,33]$, although there are quantitative differences in the extent of TGF- $\beta$ upregulation $[32,34]$, which may be related to a differential effect of Tac on the expression of TGF- $\beta$ receptors [35] and also due to the fact that FKBP12, the carrier protein for Tac, is a negative regulator of the type I TGF- $\beta$ receptor [36]. The clinical significance of the increased TGF- $\beta$ expression in the four patients is unclear. Based on the link between CNI toxicity and TGF- $\beta$, our current observation is cause for concern since it could be a harbinger of future FIB. Although we attempted to identify predictors of increasing TA/ FIB, the size of our study sample was limited and did not allow the use of multivariate analyses. We did find that the study subjects that had a progression of TA/FIB were younger. The average inter-biopsy Tac trough was also higher in the cohort that had worsening histology compared to those with no histological changes, but this difference was not statistically significant. Our study was also limited by the lack of serial biopsies in controls with SRNS who were not receiving Tac, which would have facilitated us in sorting out the differences in histological findings between the effect of the natural progression of the underlying renal disease and the effect of Tac. Such repeat biopsies are not considered a standard of care. Moreover, Tac is the only therapy we use in children with SRNS and, consequently, there was no control population that could be studied. Nevertheless, we feel that this study provides valuable information to the practicing nephrologist since it demonstrates the success that can be achieved using Tac in North American children with SRNS, with a low risk of clinical toxicity. A longer follow-up is necessary to monitor renal function in children treated with Tac. Until such data are available, the lowest possible dose of Tac necessary to maintain remission should be used, especially in younger children.

In conclusion, Tac may be a safe and effective alternative in inducing remission in children with SRNS. The risk of subclinical nephrotoxicity with Tac as well as the risk of progressive chronic kidney disease in the absence of remission being achieved need to be discussed with families, and an informed decision must be made by the clinical team.

Acknowledgements This study was funded by a grant from the Children's Miracle Network. The data, in part, were presented in abstract form at the annual meetings of the American Society of Nephrology in 2003 and 2007 and at the Western Tri-Society meeting in 2008.

Open Access This article is distributed under the terms of the Creative Commons Attribution Noncommercial License which permits any noncommercial use, distribution, and reproduction in any medium, provided the original author(s) and source are credited.

\section{References}

1. McBryde KD, Kershaw DB, Smoyer WE (2001) Pediatric steroidresistant nephrotic syndrome. Curr Probl Pediatr Adolesc Health Care 31:280-307
2. Cattran DC, Rao P (1998) Long-term outcome in children and adults with classic focal segmental glomerulosclerosis. Am J Kidney Dis 32:72-79

3. Troyanov S, Wall CA, Miller JA, Scholey JW, Cattran DC (2005) Focal and segmental glomerulosclerosis: definition and relevance of a partial remission. J Am Soc Nephrol 16:1061-1068

4. Tarshish P, Tobin JN, Bernstein J, Edelmann CM Jr (1996) Cyclophosphamide does not benefit patients with focal segmental glomerulosclerosis. A report of the international study of kidney disease in children. Pediatr Nephrol 10:590-593

5. Elhence R, Gulati S, Kher V, Gupta A, Sharma RK (1994) Intravenous pulse cyclophosphamide-a new regime for steroid-resistant minimal change nephrotic syndrome. Pediatr Nephrol 8:1-3

6. Gregory MJ, Smoyer WE, Sedman A, Kershaw DB, Valentini RP, Johnson K, Bunchman TE (1996) Long-term cyclosporine therapy for pediatric nephrotic syndrome: a clinical and histologic analysis. J Am Soc Nephrol 7:543-549

7. Niaudet P (1994) Treatment of childhood steroid-resistant idiopathic nephrosis with a combination of cyclosporine and prednisone. French society of pediatric nephrology. J Pediatr 125:981-986

8. Mendoza SA, Reznik VM, Griswold WR, Krensky AM, Yorgin PD, Tune BM (1990) Treatment of steroid-resistant focal segmental glomerulosclerosis with pulse methylprednisolone and alkylating agents. Pediatr Nephrol 4:303-307

9. Bajpai A, Bagga A, Hari P, Dinda A, Srivastava RN (2003) Intravenous cyclophosphamide in steroid-resistant nephrotic syndrome. Pediatr Nephrol 18:351-356

10. Hino S, Takemura T, Okada M, Murakami K, Yagi K, Fukushima K, Yoshioka K (1998) Follow-up study of children with nephrotic syndrome treated with a long-term moderate dose of cyclosporine. Am J Kidney Dis 31:932-939

11. Mahmoud I, Basuni F, Sabry A, El-Husseini A, Hassan N, Ahmad NS, Elbaz M, Moustafa F, Sobh M (2005) Single-centre experience with cyclosporin in 106 children with idiopathic focal segmental glomerulosclerosis. Nephrol Dial Transplant 20:735-742

12. Sairam VK, Kalia A, Rajaraman S, Travis LB (2002) Secondary resistance to cyclosporin A in children with nephrotic syndrome. Pediatr Nephrol 17:842-846

13. Trompeter R, Filler G, Webb NJ, Watson AR, Milford DV, Tyden G, Grenda R, Janda J, Hughes D, Ehrich JH, Klare B, Zacchello G, Bjorn Brekke I, McGraw M, Perner F, Ghio L, Balzar E, Friman S, Gusmano R, Stolpe J (2002) Randomized trial of tacrolimus versus cyclosporin microemulsion in renal transplantation. Pediatr Nephrol 17:141-149

14. Filler G, Grygas R, Mai I, Stolpe HJ, Greiner C, Bauer S, Ehrich JH (1997) Pharmacokinetics of tacrolimus (FK 506) in children and adolescents with renal transplants. Nephrol Dial Transplant 12:1668-1671

15. Meier-Kriesche HU, Bonilla-Felix MA, Ferris ME, Swinford R, Kahan BD, Brannan P, Portman RJ (1999) A limited sampling strategy for the estimation of Neoral AUCs in pediatric patients. Pediatr Nephrol 13:742-747

16. Schwartz GJ, Brion LP, Spitzer A (1987) The use of plasma creatinine concentration for estimating glomerular filtration rate in infants, children, and adolescents. Pediatr Clin North Am 34:571-590

17. Cuhaci B, Kumar MS, Bloom RD, Pratt B, Haussman G, Laskow DA, Alidoost M, Grotkowski C, Cahill K, Butani L, Sturgill BC, Pankewycz OG (1999) Transforming growth factor-beta levels in human allograft chronic fibrosis correlate with rate of decline in renal function. Transplantation 68:785-790

18. Lilova MI, Velkovski IG, Topalov IB (2000) Thromboembolic complications in children with nephrotic syndrome in Bulgaria (1974-1996). Pediatr Nephrol 15:74-78

19. Braun MC, Stablein DM, Hamiwka LA, Bell L, Bartosh SM, Strife CF (2005) Recurrence of membranoproliferative glomerulonephritis type II in renal allografts: The North American Pediatric Renal Transplant Cooperative Study experience. J Am Soc Nephrol 16:2225-2233 
20. Butani L, Polinsky MS, Kaiser BA, Baluarte HJ (1999) Predictive value of race in post-transplantation recurrence of focal segmental glomerulosclerosis in children. Nephrol Dial Transplant 14:166-168

21. Hariharan S, Adams MB, Brennan DC, Davis CL, First MR, Johnson CP, Ouseph R, Peddi VR, Pelz CJ, Roza AM, Vincenti F, George V (1999) Recurrent and de novo glomerular disease after renal transplantation: a report from Renal Allograft Disease Registry (RADR). Transplantation 68:635-641

22. Hulton SA, Jadresic L, Shah V, Trompeter RS, Dillon MJ, Barratt TM (1994) Effect of cyclosporin A on glomerular filtration rate in children with minimal change nephrotic syndrome. Pediatr Nephrol 8:404-407

23. Myers BD, Sibley R, Newton L, Tomlanovich SJ, Boshkos C, Stinson E, Luetscher JA, Whitney DJ, Krasny D, Coplon NS, Perlroth MG (1988) The long-term course of cyclosporine-associated chronic nephropathy. Kidney Int 33:590-600

24. Shihab FS, Andoh TF, Tanner AM, Noble NA, Border WA, Franceschini N, Bennett WM (1996) Role of transforming growth factor-beta 1 in experimental chronic cyclosporine nephropathy. Kidney Int 49:1141-1151

25. Habib R, Niaudet P (1994) Comparison between pre- and posttreatment renal biopsies in children receiving ciclosporine for idiopathic nephrosis. Clin Nephrol 42:141-146

26. Loeffler K, Gowrishankar M, Yiu V (2004) Tacrolimus therapy in pediatric patients with treatment-resistant nephrotic syndrome. Pediatr Nephrol 19:281-287

27. Bhimma R, Adhikari M, Asharam K (2006) Steroid-resistant nephrotic syndrome: the influence of race on cyclophosphamide sensitivity. Pediatr Nephrol 21:1847-1853

28. Gulati S, Prasad N, Sharma RK, Kumar A, Gupta A, Baburaj VP (2008) Tacrolimus: a new therapy for steroid-resistant nephrotic syndrome in children. Nephrol Dial Transplant 23:910-913
29. Audard V, Larousserie F, Grimbert P, Abtahi M, Sotto JJ, Delmer A, Boue F, Nochy D, Brousse N, Delarue R, Remy P, Ronco P, Sahali D, Lang P, Hermine O (2006) Minimal change nephrotic syndrome and classical Hodgkin's lymphoma: report of 21 cases and review of the literature. Kidney Int 69:2251-2260

30. Stephan JL, Deschenes G, Perel Y, Bader-Meunier B, Brunat-Mentigny M, Lejars O, Lamagneres JP (1997) Nephrotic syndrome and Hodgkin disease in children: a report of five cases. Eur J Pediatr 156:239-242

31. Pankewycz OG, Miao L, Isaacs R, Guan J, Pruett T, Haussmann G, Sturgill BC (1996) Increased renal tubular expression of transforming growth factor beta in human allografts correlates with cyclosporine toxicity. Kidney Int 50:1634-1640

32. Khanna A, Plummer M, Bromberek C, Bresnahan B, Hariharan S (2002) Expression of TGF-beta and fibrogenic genes in transplant recipients with tacrolimus and cyclosporine nephrotoxicity. Kidney Int 62:2257-2263

33. Roos-van Groningen MC, Scholten EM, Lelieveld PM, Rowshani AT, Baelde HJ, Bajema IM, Florquin S, Bemelman FJ, de Heer E, de Fijter JW, Bruijn JA, Eikmans M (2006) Molecular comparison of calcineurin inhibitor-induced fibrogenic responses in protocol renal transplant biopsies. J Am Soc Nephrol 17:881-888

34. Bing P, Maode L, Li F, Sheng H (2006) Comparison of expression of TGF-beta1, its receptors TGFbeta1R-I and TGFbeta1R-II in rat kidneys during chronic nephropathy induced by cyclosporine and tacrolimus. Transplant Proc 38:2180-2182

35. Waiser J, Dell K, Kreutzkamp J, Bohler T, Budde K, Peters H, Neumayer HH (2006) FK506, transforming growth factor-beta1 and mesangial matrix synthesis: parallels and differences compared with cyclosporine A. Cytokine 33:59-65

36. Wang T, Donahoe PK (2004) The immunophilin FKBP12: a molecular guardian of the TGF-beta family type I receptors. Front Biosci 9:619-631 